\title{
COVID-19, sex, and gender in China: a scoping review
}

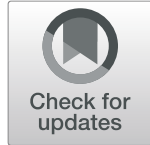

\author{
Huiyun Feng ${ }^{1}$, Connie Cai Ru Gan², Diego Leiva', Bao Ling Zhang ${ }^{3}$ and Sara E. Davies ${ }^{1 *}$ (D)
}

\begin{abstract}
Background: During the course of the COVID-19 pandemic, states were called upon by the World Health Organization to introduce and prioritise the collection of sex-disaggregated data. The collection of sexdisaggregated data on COVID-19 testing, infection rates, hospital admissions, and deaths, when available, has informed our understanding of the biology of the infectious disease. The collection of sex-disaggregated data should also better inform our understanding of the gendered impacts that contribute to risk of exposure to COVID19. In China, the country with the longest history of fighting the COVID-19 infection, what research was available on the gender-differential impacts of COVID-19 in the first 6 months of the COVID-19 pandemic?

Methods: In this scoping review, we examine the first 6 months (January-June 2020) of peer-reviewed publications $(n=451)$ on sex and gender experiences related to COVID-19 in China. We conducted an exhaustive search of published Chinese and English language research papers on COVID-19 in mainland China. We used a COVID-19 Gender Matrix informed by the JPHIEGO gender analysis toolkit to examine and illuminate research into the gendered impacts of COVID-19 within China.

Results: In China, only a small portion of the COVID-19-related research focused on gender experiences and differences. Near the end of the six-month literature review period, a small number of research items emerged on women healthcare workers, women's mental health, and pregnant women's access to care. There was an absence of research on the gendered impact of COVID-19 amongst populations. There was minimal consideration of the economic, social and security factors, including gender stereotypes and expectations, that affected different populations' experiences of infection, treatment, and lockdown during the period of review.
\end{abstract}

Conclusion: At the outset of health emergencies in China, gender research needs to be prioritised during the first stage of an outbreak to assist with evaluation of the most effective public health measures, identifying access to healthcare and social welfare barriers amongst priority communities. Gender stereotypes and gendered differences lead to different patterns of exposure and treatment. The exclusion of this knowledge in real time affects the design of effective prevention and recovery.

Keywords: Sex-disaggregated data, China, COVID-19, Gendered impacts

\section{Background}

Tracking sex and gender in real time of COVID-19

The collection of sex-disaggregated health data has been a strong recommendation of the Inter-Agency and

\footnotetext{
* Correspondence: sara.davies@griffith.edu.au

'School of Government and International Relations, Griffith University, Nathan, Brisbane, QLD, Australia

Full list of author information is available at the end of the article
}

Expert Group on Sustainable Development Goal Indicators (IAEG-SDGs) and the World Health Organization (WHO) National Action Plan for Health Security [1]. The 2019 Novel Coronavirus Strategic Preparedness and Response Plan, published by the WHO on 4 February 2020, emphasised: "Disaggregated data on age, sex, pregnancy status and outcome (as appropriate) should be reported" [2]. However, as reported by Global Health

C The Author(s). 2022 Open Access This article is licensed under a Creative Commons Attribution 4.0 International License, which permits use, sharing, adaptation, distribution and reproduction in any medium or format, as long as you give appropriate credit to the original author(s) and the source, provide a link to the Creative Commons licence, and indicate if changes were made. The images or other third party material in this article are included in the article's Creative Commons licence, unless indicated otherwise in a credit line to the material. If material is not included in the article's Creative Commons licence and your intended use is not permitted by statutory regulation or exceeds the permitted use, you will need to obtain permission directly from the copyright holder. To view a copy of this licence, visit http://creativecommons.org/licenses/by/4.0/ The Creative Commons Public Domain Dedication waiver (http://creativecommons.org/publicdomain/zero/1.0/) applies to the data made available in this article, unless otherwise stated in a credit line to the data. 
5050, "no single country is reporting sex disaggregated data across the key indicators that show who is getting tested, sick and dying from COVID-19." This means that we do not know "the sex of roughly 4 in 10 cases and 3 in 10 deaths globally" [3].

The collection of sex-disaggregated data informs realtime understanding of the biology of an infectious disease as well as the social and economic factors that contribute to risk of exposure [4, 5]. For the ongoing COVID-19 pandemic, the absence of sex-disaggregated data remains an information black hole [6]: Is the biological risk of infection the same for women and men? Are more women getting tested than men? Are women observing social distancing protocols more than men? Research has shown that sex-disaggregated data from testing to fatalities improves the targeting of risk communication, sentinel surveillance, and treatments [4]. For example, sex-disaggregated data can reveal important data about the COVID-19 clinical pathway: who is turning up for testing, who is requiring hospitalisation, and who is dying in higher numbers.

For more empirical and policy relevant research, a gender analysis of health emergencies has the "potential to offer new perspectives, pose new questions and, importantly, enhance social equalities by ensuring that research findings are applicable across the whole of society" [7]. Sex refers to the biological attributes that distinguish organisms as male, female, intersex and hermaphrodite (ibid). Gender refers to psychological, social and cultural factors that shape attitudes, behaviours, stereotypes, technologies and knowledge (ibid). It is vital to understand how gender norms are expressed during crisis because "they play a role in shaping women and men's (often unequal) access to resources and freedoms, thus affecting their voice, power and sense of self" [8].

Understanding the local gendered effects of COVID19 in real time requires attention to equal participation and representation during the health emergency response $[8,9]$. Local risk communication and information may have heteronormative gender norms that affect how individuals view their responsibility to manage risk individually and as carers, i.e. who needs to provide home schooling, who needs to work, who needs to go shopping. Gender inequalities may determine an individual's access to health services and this knowledge can inform social policy which can, in turn, complement public health measures to ensure that populations are not taking on additional health risks due to unequal economic and social burdens during lockdown periods [10].

China was the first country to report the outbreak of the virus on 31 December 2019; and it was one of the first countries to recover from the first wave of the virus. In March 2020, the Asia Pacific Gender in Humanitarian Action Working Group recommended that all states in the Asia Pacific needed to prioritise the collection of disaggregated data related to the outbreak by "sex, age, and disability"; and this data needed to be analysed in order to "understand the gendered differences in exposure and treatment and to design differential preventive measures" [11].

In December 2019, the Chinese government had just ratified and adopted the Basic Healthcare and Health Promotion Law, which guaranteed Chinese citizens' equal access to basic health care services, including a particular emphasis on child and maternal health. Prior to the outbreak of COVID-19, the National Health Commission had been pursuing a range of improvements to its collection and analysis of health data, including the introduction of national level sexdisaggregated data. Over the last 10 years, the Chinese government has progressed a range of gender equality laws in the workplace and recently introduced an antidomestic violence law. However, in practice, social attitudes to gender equality and women's empowerment have been described as requiring more awareness. In a survey of men's and women's attitudes on vulnerability to climate change and disaster risks, it was found that women have "less decision-making power on issues other than daily expenses" and "women have fewer opportunities to participate in their communities' public affairs" [12]. Moreover, the representation of women in national and sub-national discussions on disaster risk and reduction tends to position women as "vulnerable" rather than "active agents" [13]. The UN, in its 2019 China Annual Report also noted the need to "strengthen the evidence base and understanding of China's progress on international, regional and national commitments towards gender equality and women's empowerment" [14]. In the same report, UN Women documented ongoing work to "tackle social norms and stereotypes that sustain gender inequality and trigger gender based violence" [15].

Any emergency, including health emergencies, give rise to gendered experiences of infection, illness, vulnerability, and recovery [4]. Gendered experiences overlap with age, income, ethnicity, and disability. These experiences and differences interact to create differentiated risks of exposure amongst populations. Gender analysis, which includes the analysis of overlapping themes like social, economic, and physical security, pre-existing health conditions and access to care, help public health officials identify and understand how different populations will interpret and respond to public health measures [6]. Sex, age and disability disaggregated data, on their own will not reveal the social norms and stereotypes that dictate how different populations respond to public health measures and lockdown orders. A health emergency places stress on pre-existing inequalities and 
discrimination. As such, a health emergency can initiate and exacerbate inequality and discrimination [9]. Emergency response measures, while necessary, can place different groups into situations that are dangerous or harmful. Rapid research into gender, as well as ethnicity, disability, age, and economic experiences during health emergencies is vital to identify the healthcare measures, social supports, and protections needed to ensure public health compliance and equitable recovery. This paper examines the real-time research that was being conducted on COVID-19, sex, and gender during China's first wave of infections.

\section{Methods}

A scoping review method was adopted to examine the volume, variety and nature of the evidence on COVID19, sex and gender in China. The benefit of a scoping review is that it is useful to identify gaps in the rapid research published that is intended to assist the planning of public health response and provide directions for commissioning future research [16]. Our interest was in ascertaining whether the February 2020 call for states to provide sex-disaggregated data also facilitated a growth in gender analysis of the COVID-19 pandemic in locations first affected such as China. The scoping review examined the first 6 months (January-June 2020) of peerreviewed publications on the primary (COVID-19 infection and illness) and secondary effects (social welfare and security) of COVID-19 on sex and gender in China, the country with the longest history of fighting the COVID-19 infection.

Global and local research publication sources were searched using context-sensitive search terms and a combined electronic and manual search was conducted to identify primary studies for this scoping review. Eligible peer-reviewed literature was identified through Web of Science and Google Scholar (for English language literature); CNKI, WanFang, Weipu and Google Scholar (for Chinese literature). The search terms covered all areas, including Medical Subject Headings $(\mathrm{MeSH})$ terms, subject headings and keywords. The search strategy in the proposed databases was based on the search syntax published from 31 December 2019 to 30 June 2020 (see Supplement A). ${ }^{1}$

The screening and study selection phase involved several steps. First, two reviewer coders independently screened titles and abstracts to determine the inclusion status. To qualify for the review, studies had to describe

\footnotetext{
${ }^{1}$ For the Google search, the authors reviewed the first 200 results yielded sorted by relevance. For the Chinese literature, the authors selected studies published in the Guide to the Core Journals of China 2019 (version 8). The guide provides comprehensive comments on the quality and level of academic influence of Chinese periodicals. Only accepted and published studies were included in this study.
}

the effects of COVID-19 (or SARS-Cov-2) with reference to one or more of the following keywords: male/men or female/women or gender. Second, full text of any items with potential to meet the review inclusion criteria was obtained and assessed against the review inclusion criteria by the same two coders (see Table 1). Non research articles were excluded, such as editorials, commentaries, reviews, book chapters, news and blogposts. Discordant views were resolved by consensus or by reference to a third coder.

The design of the scoping review protocol used was derived from the guidance published by Arksey and O'Malley [17] and data extraction tools (including data extraction sheets for English and Chinese studies that were developed and adapted to the review question). Data on study settings, participants, methods of data collection and findings were extracted from the included studies by one author and checked by another. Separate data extraction sheets were developed and piloted for both languages. Disagreements on classification and thematic coding were resolved by group discussions.

The data analysis applied both quantitative (i.e. frequencies and percentages) and qualitative (i.e. thematic analysis) methods. The authors analysed each research publication to establish the degree to which sex and gender-related considerations or both were researched when compiling an understanding of the pandemic (in real time).

The final sample includes studies covering a variety of study designs: descriptive epidemiological studies, clinical characteristic and interventional studies (eg. diagnosis, treatment, before and after) as primary effect studies; studies examining the secondary impact of SARS-CoV-2 on one or more sexes; as well as studies that researched the secondary impact of SARS-Cov-2 (e.g. movement restriction) as part of an intervention to change some aspect of policy or practice. The retrieved studies were categorised under five themes identified in a rapid gender assessment matrix designed for the COVID-19 pandemic [15]. The five areas selected in the matrix aim to identify what knowledge, experiences and responses to the COVID-19 outbreak were informed by risk (of exposure), illness, and access to health services, as well as social, economic, and security conditions. The gender and health matrix methodology organises research into five categories that seek to uncover where gender research is concentrated and/or missing: individual risk and vulnerability, experience of illness and treatment, general access to health services, social impacts of crisis, and security impacts of crisis. The matrix, as an analytical tool, permits examination of concentration of gendered investigation and studies during an event, such as the COVID-19 pandemic, and serves to highlight knowledge gaps. Below, for each category we describe the 
Table 1 Selection of studies on inclusion and exclusion criteria

\begin{tabular}{|c|c|c|}
\hline & Inclusion criteria & Exclusion criteria \\
\hline Publication types & Peer-reviewed, empirical studies & $\begin{array}{l}\text { Editorials, commentaries, review, Social media posts } \\
\text { news articles, press release, blogposts, conference } \\
\text { proceedings, dissertations), book chapter, blog post }\end{array}$ \\
\hline Quality/ Evidence & $\begin{array}{l}\text { Publications were categorised into core and } \\
\text { non-core journals according to Peking } \\
\text { University List of Core Journal } 2018 \text { (version 8) }\end{array}$ & \\
\hline Language & English or Simplified Chinese $\mathrm{e}^{\mathrm{b}}$ & Full text not in either English or Chinese \\
\hline Database/ Search Engine & $\begin{array}{l}\text { English literature: Web of Science, Google Scholar } \\
\text { Chinese literature: CKNI, WanFang, Weipu, } \\
\text { Google Scholar } \\
\text { site: .gov.cn; site: .org }\end{array}$ & \\
\hline Published date & aDecember 31st 2019 to June 30th 2020 & Online first (without full text) \\
\hline Study Population & Mainland China & Hong Kong, Macau, Taiwan and overseas Chinese \\
\hline
\end{tabular}

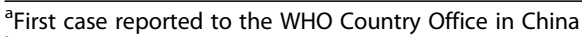

${ }^{b}$ Simplified Chinese is the official written Chinese language. There are two standard character sets of Chinese written language: Simplified and Traditional.

Simplified Chinese characters are used in Mainland China, which is the scope of this study

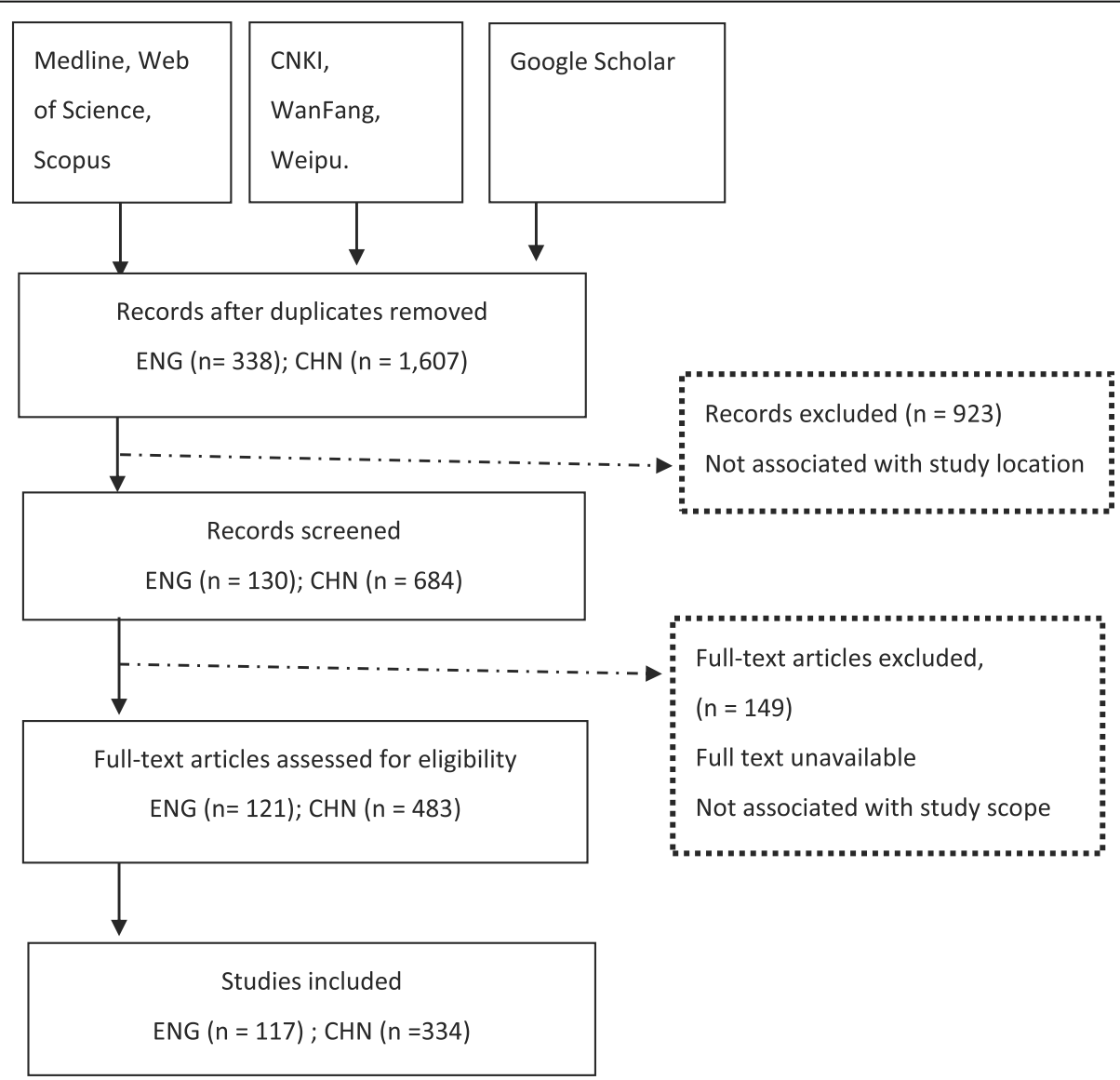

Fig. 1 PRISMA flow diagram 
general findings from the assignment of articles under each theme [18].

The vast literature was grouped, analytically, under the five themes through quantifiable means. The authors frequently collaborated to ensure shared understanding of the thematic areas to analyse and group each publication. The authors do not claim to comment on the quality of the studies, nor evaluate the strength of the evidence or data presented in the publications. A limitation of this research is that the included studies did not examine men, transgender, or non-binary gendered experiences.

\section{Results}

From the 2,083 articles initially identified, 451 empirical studies met the inclusion criteria (see Table 1). The eligible studies are reported in the PRISMA flow diagram (Fig. 1) and their main characteristics are outlined in Table 2. Out of the 451 studies included in this review, $74 \%(n=334)$ were published in Chinese and 26\% ( $n=$ 117) were in English. The majority of articles were published in April 2020, with most of the research conducted in Hubei, followed by Sichuan and Guangdong.

The co-occurrence of key terms from retrieved studies highlights the primary focus of the publications and denotes research topics (Fig. 2A and B). Some of the cooccurrence key terms are related to epidemiological

Table 2 Description of included studies

\begin{tabular}{lll}
\hline Variable & English & Chinese \\
\hline Total - N & 117 & 334 \\
Study Published date & & \\
2020 (Did not specify month) & 4 & 10 \\
Jan & 1 & - \\
Feb & 7 & 46 \\
March & 23 & 79 \\
April & 36 & 100 \\
May & 33 & 66 \\
June & 9 & 33 \\
Sample size - median (range) & $149(1-82,858)$ & $84(1-44,038)$ \\
Study design & & 190 \\
Case study & 11 & 52 \\
Cross-sectional & 26 & 12 \\
Controlled before-after & 1 & \\
Cohort study (retro) & 65 & 83 \\
Data collection methods & & 319 \\
Survey & 29 & 4 \\
Medical record & 81 & \\
Interview & 0 & \\
Document / Surveillance Data & 11 & \\
\hline
\end{tabular}

characteristics including outbreak, male, female, mortality, diabetes and medical staff. Others are related to clinical diagnosis such as duration, anxiety, computer tomography and fever clinic. The Chinese and English language research papers included sex as a variable but the papers, on the whole, failed to analyse the everyday social aspects of gender and its relationship to COVID19 infection, recovery and death.

The goal of the scoping review is to understand the extent of rapid research that engaged with the genderrelated considerations identified in the Gender Analysis and COVID-19 Matrix during the first wave of COVID-19 in China. The majority of studies (both English and Chinese papers) focused on sex differences to understand the impact of the pandemic. The review reveals very little "real time" research and consideration of whether gender, as well as disability, income, ethnicity and age, contributed to exposure, infection, and recovery $[18,19]$.

We identify two explanations for this knowledge gap. The first is that real-time research on health emergencies and their gendered effects has been identified as an analytical gap across most countries and, in turn, this has affected gender-inclusive health policy response and recovery $[6,18]$. The second explanation, based on findings from this scoping review, is that research in China tends to conflate sex and gender. Research on sexdisaggregated data is presented as findings on gender, i.e. women healthcare workers experienced more stress during COVID-19, rather than analysing whether there were gendered inequalities and differences in roles and expectations that distinguished the experiences of women healthcare workers from those of their male counterparts.

We can establish from this scoping review that, conceptually, real-time sex and gender analysis was prioritised when it intersected with health impacts and healthcare work considerations. There was little realtime published research available on the gendered impacts of COVID-19 on Chinese society in the first 6 months in China.

As detailed below, the review finds that across each of the five matrix categories, individual risk and vulnerability, experience of illness and treatment, general access to health services, social impacts of crisis, and security impacts of crisis, the research articles include sex- disaggregated data but analytically assume traditional gendered roles/activities. There are few examples of published articles that analyse the COVID-19 experience in China with the intention of understanding the "gendered differences in exposure and treatment and to design differential preventive measures" [11].

\section{Risk and vulnerability}

For this category, research is included if the study identifies individual or group risk and vulnerability of 


\section{A. Common co-occurring words among Chinese language studies}

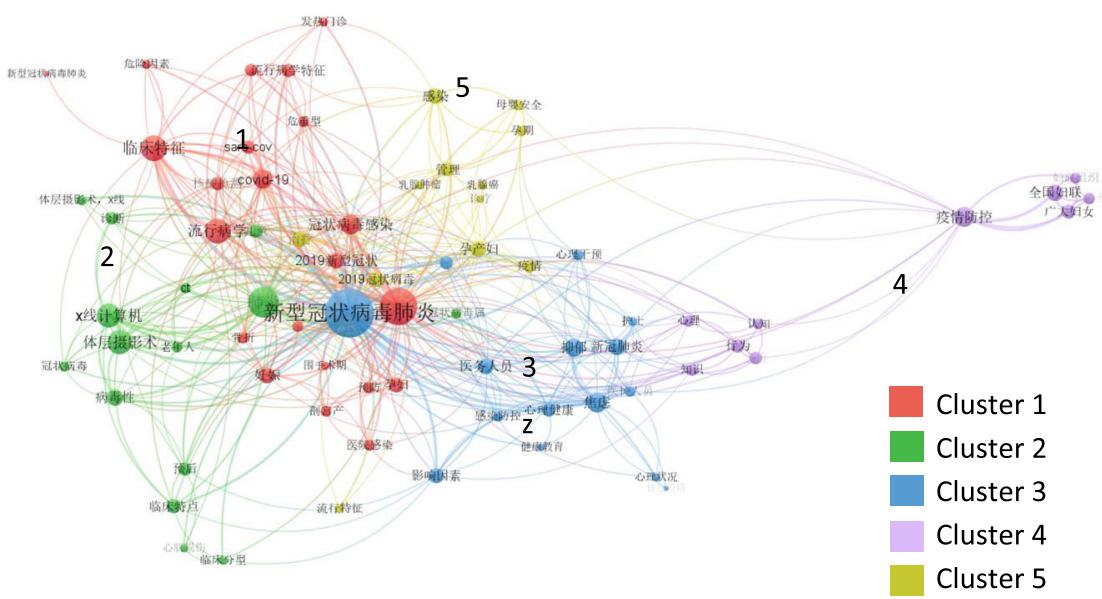

Cluster 1: Epidemiology “流行病学”, risk factor “危险因素”, fever clinic “发热门诊”, critical stage“危重型”

Cluster 2: Tomography “体层摄影术”，clinical characteristic“临床特点”，viral “病毒性”

Cluster 3: Healthcare workers“医务人员”, influence factor“影响因素”,infection control“感 染防控”, mental health“心理健康”

Cluster 4: prevention and control“疫情防控”, All-China Women's Federation“全国妇联”， knowledge “知识”, behaviour"行为”

Cluster 5: Infection“感染”, pregnant women“孕产妇”, safety of Mother-Child“母婴安全” ,breast cancer“乳腺肿瘤”

\section{B. Common co-occurring words among English language studies}

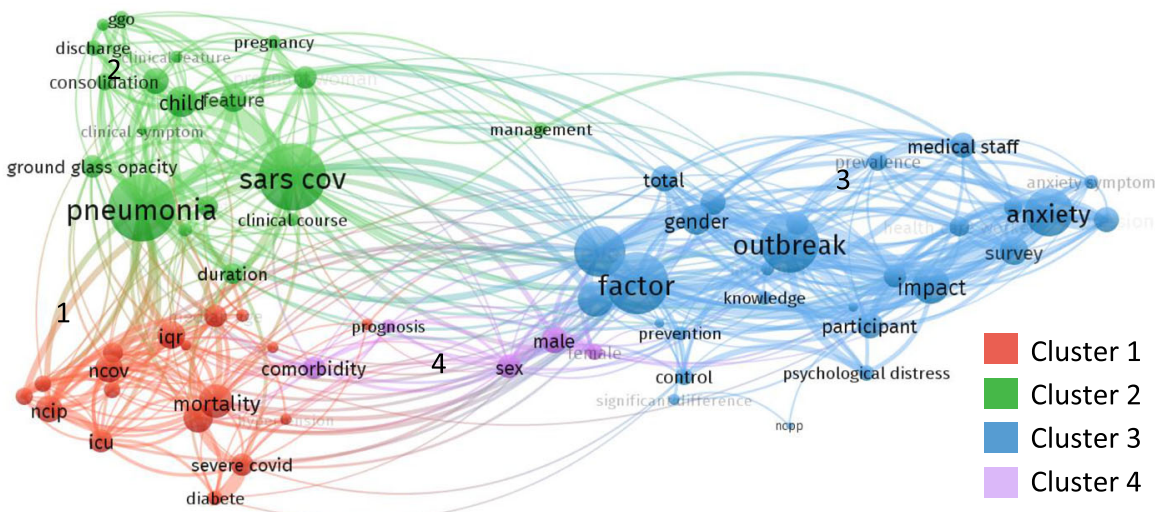

Cluster 1: Mortality, diabetes, interquartile range (IQR), severe Covid-19

Cluster 2: Pneumonia, ground-glass opacity (GGC), duration, clinical course, pregnancy Cluster 3: factor, outbreak, medical staff, anxiety

Cluster 4: comorbidity, prognosis, sex, male

Fig. 2 A Common co-occurring words among Chinese language studies. B Common co-occurring words among English language studies 
infection. We included articles identifying individual high-risk of COVID-19 infection, including pregnant persons, gender-specific conditions such as breast cancer, cervical cancer, uterine cancer, ovarian cancer, prostate cancer, neurotypical, congenital, birth trauma, genetic and/or hereditary conditions, age (elderly, youth, child, infant), and autoimmune conditions (HIV, SLE, NLR. AFL). In the first stage of the outbreak, the majority of sex-disaggregated studies on infection (Chinese $n=22$; English $n=7$ ) detailed the clinical characteristics of COVID-19 patients with flu or fever symptoms and an association with pre-existing conditions such as breast cancer [20], cardio vascular diseases [21], pneumonia and diabetes [22]. The source of these studies were medical records, surveillance data, or a combination of both. Overall, the risk of COVID-19 infection to men is presented as higher than women, but certainty of sex-disaggregated results was uneven due to inconsistent participant recruitment and diagnostic methods.

Half of all published articles identified in this review examined sex-disaggregated risk and vulnerability to SARS-Cov-2 $(n=235)$, but only one study examined whether gendered roles could be associated with risk of infection. The majority of research consisted of sexdisaggregated studies (Chinese and English) on the risk of COVID-19 to medical staff $(n=82)$, the elderly $(n=$ $29)$, children and infants $(n=34)$, pregnant women $(n=$ $18)$ and others $(n=14)$. Publications on the first wave of the outbreak examined the impact of COVID-19 pandemic on women healthcare workers and carers in Hubei [23]. Women healthcare workers are the majority of healthcare workers across China, including Hubei. Some studies examined the prevalence of PPE-related skin injuries among nurses [24]. Several research papers were published on women healthcare workers' struggle to work under the measures taken by the authorities [25]. There was a noticeable increase in the number of studies on healthcare workers' mental health assessed through online surveys focused on sleep quality, anxiety and stress [26, 27]. These studies tended to focus on women healthcare workers. There was little examination of whether this high volume of women healthcare workers experiencing stress and precarity is due to social gender norms that associate women with vulnerability (i.e. it is more socially acceptable for women to discuss personal vulnerabilities than men). There is also the fact that women healthcare workers were primarily the frontline staff, who were at high potential risk of infection due to the illness' characteristics of high transmission efficiency, rapid deterioration and pathogenicity. We note there is an absence of men and their experiences as healthcare workers at risk of infection. The multitude of papers that refer to women healthcare workers and mental illness, with lack of consideration as to whether and if men were equally affected, points to unchallenged gender stereotypes in the research publications examining the impact of COVID-19 on risk of infection and risk of associated illness.

An additional 29 studies (Chinese and English) researched the transmission mode of COVID-19: vertical transmission, nosocomial transmission, organ donation and through family cluster [28-31]. Of these studies that analysed the sex-disaggregation only one study did so with a gender lens concluding that women's uptake in care roles, higher frequency of hospital visits and household chores, makes them more vulnerable to infection [31].

\section{IIIness and treatment}

The articles in this category focussed on the clinical observations and epidemiological studies on COVID-19 including fatality rates, testing and treatment. As government policies encouraged exploring alternative treatments for COVID-19 (eg. Guangdong, Shaanxi Provincial government COVID-19 TCM treatment pilot plan), we observed a number of research papers that integrated Traditional Chinese Medicine and other alternative and complementary medicines [24, 32-38]. These studies presented no research into significant [34] sex differences in terms of diagnostic of COVID-19 confirmed cases.

There were 91 articles discussing the detection of SARS-Cov-2 through stool, gastrointestinal tract, saliva, and urine samples examined using radiology methods or laboratory that were sex-disaggregated $[39,40]$. In one study, researchers found that SARS-CoV-2 can be present in the semen of patients with COVID-19, and SARS-CoV-2 may still be detected in the semen of recovering patients [41]. There were no studies, that we could find, on gendered practices in seeking COVID-19related care and recovery. The only exception near the end of the six-month period was studies that recruited research participants who were pregnant [42-45]: 53 articles were published in this period discussing COVID19 treatment in conjunction with pregnancy.

\section{Access to health services}

For this category we included articles that analysed who sought access to health services during China's first Covid-wave lockdown. Specifically, they encompass those who sought COVID-19 testing, as well as the health, social or/and psychological supports available to populations during the first wave. The scale of China's lockdown during this period was immense: in Wuhan alone 11 million people were in lockdown during the period of scoping review. There were, however, no published papers examining the reorganisation of existing care services and treatments to meet specific sexual and reproductive healthcare needs, the readjustment of care 
and support for those with mental illness, the specific healthcare needs of those with disabilities, or aged care.

During this period, most articles examined healthcare service management during the outbreak for, specifically, antenatal care planning $[46,47]$, patient triage based on the risk level, admission control and measures on counteracting emergencies, and designating safe zones for non-Covid-19 patients [47-49]. There were a small number of publications on the need to ensure virtual healthcare where possible, and healthcare providers were encouraged to expand their remote care practices [5052]. For example, 233 out of 294 midwifery clinics in Guangdong province provided a COVID-19 hot-line service, and 186 clinics delivered telehealth services [52]. Near the end period of the scoping review, several studies were published discussing the transformation of routine hospital appointments for pregnant women and cancer patients (priority groups) in order to mitigate nosocomial infections [53-57].

\section{Social impacts}

Articles were examined for mention of the economic (i.e. loss of income) and social (i.e. family violence) impacts of COVID-19. Social impact studies tended to especially focus on the mental health of healthcare workers, students, and the general population (i.e. sleep quality, stress, anxiety) during lockdown (n: 126 in Chinese and English). In other words, the focus is on how these populations were managing or would manage the return to "normality" after the lockdown. The vast majority of papers in particular are concerned with healthcare workers' mental health and their return to "normal" life after the outbreak. As noted above, the majority of healthcare workers responding to COVID-19 were women (three quarters of the healthcare workforce in China are women [9]).

One study documented Post-Traumatic Stress Syndrome (PTSS) amongst the healthcare workers who worked in the COVID-19 outbreak hospitals [58]. In one study, being male was identified as a "protective" factor for depression among doctors [59]. This study "confirmed" the view that depression rates are universally higher in women, and that biological determinants, sex role changes, but also unspecified social factors might contribute to this difference [59]. One survey showed women experienced higher levels of psychological distress, and another study found women's resilience was significantly lower than men $[60,61]$. There was no examination in these studies of the social determinants, including gender norms, in seeking treatment and counselling for depression and other mental health conditions within China. Workplace roles, duties, and expectations of healthcare workers were not examined in these papers. There was no examination of the toll of double burden of homecare roles and responsibilities whilst working in a high-risk environment during a pandemic outbreak. For example, only two studies examined whether concerns with family infection-essentially bringing the virus home-was the biggest stress for medical staff [62-64].

Given the broadness of the social impact category it is striking how little knowledge was being circulated in real time about the economic and social impacts of the lockdown, and the burden of care roles and responsibilities amongst family units. Research published after this scoping review period has revealed some insights into the social and economic impacts of the Wuhan lockdown, especially on the unequal gendered experiences of this lockdown [18]. ${ }^{2}$

\section{Security impacts}

Finally, for this category we analysed articles that examined individual experience(s) of violence during the first wave, healthcare workers' physical safety, and fear of transmission (within families and communities). Only a minority of studies published on the security impacts $(n=28)$ of COVID-19 in "real time" during the first wave. The majority of the security impact studies examined individuals' fear of being in lockdown and fear of spreading the virus amongst family [65]. Despite realtime research in other first wave affected locations revealing domestic violence as an immediate consequence of lockdown measures, there was only one published paper documenting this experience in China [18]. Hongwei Bao documented the "Anti-domestic Violence Little Vaccine" campaign as a demonstration of how Chinese feminists engaged with the issues of domestic violence and women's rights during the pandemic. This publication was the only one identified in the six-month period that studied individual experiences of violence during the first wave [66].

\section{Discussion}

Our scoping research showed there was minimal analysis of gender differences in the "first wave" of published papers on the COVID-19 outbreak in China. Sex data was mostly used for clinical analysis and not gender analysis. From the analysis of Chinese and English published literature on the COVID-19 first wave in China there were two areas where sex-disaggregated data was utilised to examine groups' experiences of COVID-19: female healthcare workers and pregnant women. Very few papers that published on these topics examined the

${ }^{2} \mathrm{~A}$ comparison of different countries analysed for gendered impacts of the COVID-19 outbreak may be viewed on the Gender and COVID-19 Matrix. https://www.genderandCOVID-19.org/matrix/ (Access 20 October 2021). 
gendered experiences amongst the populations affected by lockdown.

Research into the impact of COVID-19 on women healthcare workers' mental health was viewed from a heteronormative gender lens where women were described as more prone to anxiety and stress [67]. The fact that the majority of healthcare workers were women, and traditional gendered expectations required women to still manage family responsibilities, was only mentioned once [64]. Most of the focus was on their anxiety, depression, post-traumatic stress symptoms (PTSS) and poor sleep quality, and women's biological predisposition to stress.

Along with highlighting the particularly tough conditions which healthcare workers endured during the pandemic, several papers called for specific policy measures to protect and support them. The most common recommendation was to provide psychological support and interventions [68], such as health education and training, and to focus on the healthcare workers' safety measures (i.e. provision of protective equipment) [69-78]. Individual level concerns about family welfare during their absence [77], individual power to challenge employment conditions [79-81], and physical challenges posed by the lockdown were ignored or side-lined in the majority of published research.

As the rate of infection of healthcare workers in $\mathrm{Wu}$ han grew during the first wave, the proportion of women in infection cases also increased. There was a need to strategically encourage and mobilise healthcare workers between provinces and cities. This required research into training, mobilisation, infection control and, related to the above, addressing attendant mental health challenges that emerged with relocation, long hours, and quarantine. The literature, however, seemed to assume these challenges were due to women's disposition to mental illness rather than the fact that women healthcare workers make up the majority of the healthcare workforce but would experience economic, social and security challenges unique to gendered roles and expectations within Chinese society [82, 83].

The scoping review found a common association between women healthcare workers and mental health. Stress and anxiety due to uncertainty, fear, and long working hours were attributed to women healthcare workers more than to their male counterparts. These findings appear to be more attributable to gender stereotypes.

Real-time research on gender determinants for infection, risk and vulnerability was minimal. This finding is consistent with other studies that have found gender research gaps in China's response to other health epidemics including HIV/AIDS [84]. The only exception was pregnant women, but these studies were not gender studies of their experiences and stereotypes encountered during COVID-19 lockdown. The studies focused on pregnant women as a priority group as they need to access hospital facilities regularly and are at higher risk of infection in hospital. Coupled with this is a (gendered) cultural tradition that emphasises the importance of "mother and child" with most families still having low fertility rates. Protecting the health concerns and needs of expecting mums and the unborn is a very high priority in China [19].

There may be practical factors at play that determined the volume and thematic focus of the outputs: the publication process is shorter for public health and medical academic articles compared to social science journals (which tend to be the primary location for gender publications). Research about gender issues requires different methods of data collection and analysis which may be lacking amongst the disciplines publishing rapid research in the first stages of a health emergency. The published research focused on sex disaggregation to explain experiences of COVID-19 infection and lockdown impacts. It is important sex-disaggregated data is available in real time but this data alone is not sufficient for rapid gender analysis. The next step is to promote rapid research that can understand how gender drives behaviours, expectations, and resilience during an outbreak [85].

\section{Conclusion}

At the outset of a health emergency, rapid research needs to pay attention to the gendered roles attached to infection control, healthcare access, risk interventions and social welfare.

In China, nationwide collection of sex-disaggregated data was not initially prioritised at the onset of the outbreak. This was not unique to China. The sexdisaggregated research published during the first wave revealed high rates of infection amongst healthcare workers, the majority of them being women. Women healthcare workers' mental stress may have had nothing to do with their "biological tendencies" but their real risk of exposure. The exclusion of this knowledge in real time affects the design of effective prevention and recovery. There was very little research on the social, security, and economic drivers of the pandemic during the first wave of COVID-19 in China. The knowledge gaps that occur in the first wave of an outbreak may be tied to the research and policy directives prioritised at the start of the pandemic and in the recovery stages. Capturing sexdisaggregated data is the first step. The next step is to examine the how gender stereotypes and gendered differences lead to different patterns of exposure and treatment in China. There needs to be a research-policy feedback loop that values this research to ensure the design of even more effective policy. Gender analysis 
during the first stage of an outbreak can assist with evaluation of most effective public health measures, identify access to health barriers amongst priority communities, and serve to create a feedback loop for more effective gender-inclusive policy and recovery.

\section{Abbreviations}

HCWs: Healthcare Workers; PRISMA: Preferred Reporting Items for Systematic Reviews and Meta-Analysis; TCM: Traditional Chinese Medicine; IAEGSDGs: Inter-Agency and Expert Group on Sustainable Development Goals Indicators

\section{Supplementary Information}

The online version contains supplementary material available at https://doi. org/10.1186/s12992-022-00804-w.

Additional file 1. Keywords and search syntax.

\section{Acknowledgements}

We acknowledge Julia Smith and Clare Wenham, co-chief investigators of the grant that funded this research: Understanding and mitigating real-time differential gendered effects of the COVID-19 outbreak, Canadian Institutes of Health Research (Grant Number 170639).

\section{Authors' contributions}

CCRG, DL and BLZ read and screened articles for inclusion. All authors reviewed and analysed the extracted data. HF, CCRG and SD drafted the manuscript. All the authors read and approved the final manuscript.

\section{Funding}

This work was supported by the Canadian Institutes of Health Research under grant number 170639

\section{Availability of data and materials}

Datasets are available through the corresponding author upon request.

\section{Declarations}

Ethics approval and consent to participate

Not applicable.

\section{Consent for publication}

Not applicable.

\section{Competing interests}

No potential conflict of interest was reported by the author(s).

\section{Author details}

'School of Government and International Relations, Griffith University, Nathan, Brisbane, QLD, Australia. ${ }^{2}$ Centre for Environment and Population Health, Griffith University, Qld, Nathan, Australia. ${ }^{3}$ Institute for Hospital Management, Tsinghua University, Shenzhen, China.

Received: 20 April 2021 Accepted: 11 January 2022

Published online: 04 February 2022

\section{References}

1. World Health Organization. NAPHS for all - a country implementation guide for NAPHS: World Health Organization; 2019. Available from: http://www. who.int/ihr/publications/country_implementation_guide_for_naphs/en/. Cited 2021 Apr 8

2. World Health Organization. Strategic preparedness and response plan for the novel coronavirus: World Health Organization; 2020. Available from: https://www.who.int/publications-detail-redirect/strategic-preparedness-andresponse-plan-for-the-new-coronavirus. Cited 2021 Apr 8

3. The COVID-19 Sex-Disaggregated Data Tracker | Global Health 50/50. Available from: https://globalhealth5050.org/the-sex-gender-and-COVID-19project/the-data-tracker/. Cited 2021 Mar 1.
4. Wenham C, Smith J, Davies SE, Feng H, Grépin KA, Harman S, et al. Women are most affected by pandemics - lessons from past outbreaks. Nature. 2020;583(7815):194-8. https://doi.org/10.1038/d41586-020-02006-z.

5. Wenham C, Smith J, Morgan R. COVID-19: the gendered impacts of the outbreak. Lancet. 2020;395(10227):846-8. https://doi.org/10.1016/S0140-673 6(20)30526-2.

6. Ahmed SB, Dumanski SM. Sex, gender and COVID-19: a call to action. Can J Public Health. 2020;111(6):980-3. https://doi.org/10.17269/s41997-020-0041 7-z.

7. Tannenbaum C, Ellis RP, Eyssel F, Zou J, Schiebinger L. Sex and gender analysis improves science and engineering. Nature. 2019;575(137):137-46.

8. Cislaghi B, Heise L. Gender norms and social norms: differences, similarities and why they matter in prevention science. Social Health IIIn. 2020;42(416): 407-22.

9. Sharma V, Scott J, Kelly J, VanRooyen MJ. Prioritizing vulnerable populations and women on the frontlines: COVID-19 in humanitarian contexts. Int J Equity Health. 2020;19(1):66. https://doi.org/10.1186/s12939-020-01186-4

10. COVID-19 Global Gender Response Tracker. UNDP COVID-19 Data Futur. Platf. Available from: https://data.undp.org/gendertracker/. Cited 2021 Mar 1.

11. Asia-Pacific Gender in Humanitarian Action Working Group. The COVID-19 outbreak and gender: key advocacy points from Asia and the Pacific. 2020. Available from: https://www.humanitarianresponse.info/sites/www.humanita rianresponse.info/files/documents/files/giha_wg_advocacy_brief_covid_19_ outbreak_and_gender.pdf.

12. UN Women. Gender dimensions of vulnerability to climate change in China; 2016. p. ix. Available from: https://asiapacific.unwomen.org/-/media/field\%2 0office\%20eseasia/docs/publications/2017/01/gender-dimensions-english-r2 s.pdf?la=en\&vs=4238

13. UN Women. Gender dimensions of vulnerability to climate change in China [Internet]. 2016. p. x. Available from: https://asiapacific.unwomen.org/-/ media/field\%20office\%20eseasia/docs/publications/2017/01/genderdimensions-english-r2s.pdf?la=en\&vs=4238p.ix.

14. United Nations China. United Nations in China annual report 2019: United Nations China; 2019. p. 37. Available from: https://asiapacific.unwomen. org/-/media/field\%20office\%20eseasia/docs/publications/2020/06/2019\%20a nnual\%20report full\%20final.pdf?la=en\&vs=4510

15. United Nations China. United Nations in China annual report 2019 [Internet]. United Nations China; 2019. p. 38. Available from: https://asiapa cific.unwomen.org/-/media/field\%20office\%20eseasia/docs/publications/202 0/06/2019\%20annual\%20report full\%20final.pdf?la=en\&vs=4510.

16. Peters MDJ, Godfrey CM, Khalil H, Mclnerney P, Parker D, Soares CB. Guidance for conducting systematic scoping reviews. Int J Evid Based Healthc. 2015;13(3):141-6. https://doi.org/10.1097/XEB.0000000000000050.

17. Arksey H, O'Malley L. Scoping studies: towards a methodological framework Int J Soc Res Methodol. 2005:8:19-32. https://doi.org/10.1080/1364557032 000119616.

18. Smith J, Davies SE, Feng H, Gan CCR, Grépin KA, Harman S, et al. More than a public health crisis: a feminist political economic analysis of COVID-19. Glob Public Health. 2021;16(8-9):1364-80. https://doi.org/10.1080/17441 692.2021.1896765

19. Qiao J. What are the risks of COVID-19 infection in pregnant women. Lancet. 2020;395(10226):760-2. https://doi.org/10.1016/S0140-6736(20)303 $65-2$

20. Huang J, Hu YP, Chen C, Qi XW. Clinical challenges of breast cancer treatment during COVID-19. Zhong Guo Pu Tong Wai Ke Za Zhi. 2020:29: 153-60. https://doi.org/10.7659/j.issn.1005-6947.2020.02.006 Chinese.

21. Zhao J, Li X, Gao Y, Huang W. Risk factors for the exacerbation of patients with 2019 novel coronavirus: a meta-analysis. Int J Med Sci. 2020;17(12): 1744-50. https://doi.org/10.7150/ijms.47052.

22. Yan $Y$, Yang $Y$, Wang $F$, Ren $H$, Zhang $S$, Shi $X$, et al. Clinical characteristics and outcomes of patients with severe COVID-19 with diabetes. BMJ Open Diabetes Res Care. 2020;8(1):e001343. https://doi.org/10.1136/bmjdrc-2020 001343

23. Zheng L, Wang X, Zhou C, Liu Q, Li S, Sun Q, et al. Analysis of the infection status of healthcare workers in Wuhan during the COVID-19 outbreak: a cross-sectional study. Clin Infect Dis. 2020;71(16):2109-13. https://doi.org/1 $0.1093 /$ cid/ciaa588.

24. Jiang QX, Liu YX, Wei W, Chen AH, Bai YX, Cai YH, et al. The incidence and epidemic characteristics of medical staff's skin injuries caused by personal protective equipment for fighting against 2019-nCoV infection. Chin Gen Pract. 2020;23:1083-90 Chinese. 
25. Chen Q, Liang M, Li Y, Guo J, Fei D, Wang L, et al. Mental healthcare for medical staff in China during the COVID-19 outbreak. Lancet Psychiatry. 2020;7(4):e15-6. https://doi.org/10.1016/S2215-0366(20)30078-X.

26. Liu J, Zhu Q, Fan W, Makamure J, Zheng C, Wang J. Online mental health survey in a medical college in China during the COVID-19 outbreak. Front Psychiatry. 2020;11:459. https://doi.org/10.3389/fpsyt.2020.00459.

27. Wu K, Wei X. Analysis of psychological and sleep status and exercise rehabilitation of front-line clinical staff in the fight against COVID-19 in China. Med Sci Monit Basic Res. 2020;26:UNSP e924085.

28. Chen M, Fan P, Liu Z, Pan R, Huang S, Li J, et al. A SARS-CoV-2 familial cluster infection reveals asymptomatic transmission to children. J Infect Public Health. 2020;13(6):883-6. https://doi.org/10.1016/j.jiph.2020.05.018.

29. Chen H, Guo J, Wang C, Luo F, Yu X, Zhang W, et al. Clinical characteristics and intrauterine vertical transmission potential of COVID-19 infection in nine pregnant women: a retrospective review of medical records. Lancet. 2020;395(10226):809-15. https://doi.org/10.1016/S0140-6736(20)30360-3.

30. Peng Z, Wang J, Mo Y, Duan W, Xiang G, Yi M, et al. Unlikely SARS-CoV-2 vertical transmission from mother to child: a case report. J Infect Public Health. 2020;13(5):818-20. https://doi.org/10.1016/j.jiph.2020.04.004.

31. Liao JY, Yang ZX, Zhou T. The care role and susceptibility among female COVID-19 cases. Dian Zi Ke Ji Da Xue Bao. 2020;49:425-30 Chinese.

32. Yu SM, Cui YF, Wang ZX, Wang ZX, Wang LF, Sun YQ. Analysis on COVID-19 cases: TCM clinical analysis. Shi Jie Zhong Yi Yao. 2020;15:494-6,501. https:// doi.org/10.3969/j.issn.1673-7202.2020.04.004 Chinese.

33. Zhang $X$, Liu L, Dai GC, YeF MNL, Feng Z, et al. Clinical characteristic and TCM syndromes of 42 COVID-19 cases in Nanjing area. Nan Jing Zhong Yi Yao Da Xue Bao. 2020;36:145-8. https://doi.org/10.14148/j.issn.1672-0482.202 0.0145 Chinese.

34. Meng XZ, Wan XY, Li JC, Gong XL, Liang YQ, Gao SK, et al. Analysis of 756 cases of TCM syndromes among patients with new coronavirus pneumonia. Di Er Jun Yi Da Xue Bao. 2020;41:395-9. https://doi.org/10.16781/j.0258879x.2020.04.0395 Chinese.

35. Mao Y, Cui X, Jiang ZC, Huang HH, Zhu SJ, Wang XL. Analysis of TCM syndromes and clinical features of 24 cases of novel coronavirus pneumonia in Ankang, Shaanxi. Shan Xi Zhong Yi. 2020;41:427-428,517. https://doi.org/10.3969/j.issn.1000-7369.2020.04.006 Chinese.

36. Jiang BB, Pan J, Chen SB, Gong JB, Deng J, Liu Y, et al. Preliminary study on the tongue picture of 78 patients with novel coronavirus pneumonia. Jiang Su Zhong Yi Yao. 2020;52:84-6 Chinese.

37. Jin $Z C, Y i Y$, Yang $Y Q$. Suggested plan for diagnosis and treatment of new coronavirus pneumonia in puerperium with traditional Chinese medicine. Zhong Yi Xue. 2020;9:277-82. https://doi.org/10.12677/TCM.2020.93041 Chinese.

38. Zhou $H$, Yuan JP, Yang GS, Sun $H$, Tang WH, Yang LP, et al. A preliminary study on the diagnosis and treatment of 13 cases of novel coronavirus pneumonia in Qujing area with Integrated TCM and Western medicine. Zhong Guo Min Zu Min Jian Yi Yao. 2020;29:55-8 Chinese.

39. Hu L, Wang C. Radiological role in the detection, diagnosis and monitoring for the coronavirus disease 2019 (COVID-19). Eur Rev Med Pharmacol Sci. 2020;24(8):4523-8. https://doi.org/10.26355/eurrev_202004_21035.

40. Li Y, Xia L. Coronavirus disease 2019 (COVID-19): role of chest CT in diagnosis and management. Am J Roentgenol. 2020;214(6):1280-6. https:// doi.org/10.2214/AJR.20.22954.

41. Li D, Jin M, Bao P, Zhao W, Zhang S. Clinical characteristics and results of semen tests among men with coronavirus disease 2019. JAMA Netw Open. 2020;3(5):e208292. https://doi.org/10.1001/jamanetworkopen.2020.8292.

42. Cao D, Yin H, Chen J, Tang F, Peng M, Li R, et al. Clinical analysis of ten pregnant women with COVID-19 in Wuhan, China: a retrospective study. Int J Infect Dis. 2020;95:294-300. https://doi.org/10.1016/j.jijid.2020.04.047.

43. Wu C, Yang W, Wu X, Zhang T, Zhao Y, Ren W, et al. Clinical manifestation and laboratory characteristics of SARS-CoV-2 infection in pregnant women. Virol Sin. 2020;35(3):305-10. https://doi.org/10.1007/s12250-020-00227-0.

44. Chen L, Li Q, Zheng D, Jiang H, Wei Y, Zou L, et al. Clinical characteristics of pregnant women with COVID-19 in Wuhan, China. N Engl J Med. 2020; 382(25):e100. https://doi.org/10.1056/NEJMc2009226.

45. Mei $Y$, Luo D, Wei S, Liao X, Pan Y, Yang X, et al. Obstetric management of COVID-19 in pregnant women. Front Microbiol. 2020;11:1186. https://doi. org/10.3389/fmicb.2020.01186.

46. Yu N, Li W, Kang Q, Xiong Z, Wang S, Lin X, et al. Clinical features and obstetric and neonatal outcomes of pregnant patients with COVID-19 in Wuhan, China: a retrospective, single-centre, descriptive study. Lancet Infect Dis. 2020;20(5):559-64. https://doi.org/10.1016/\$1473-3099(20)30176-6.
47. Zhang Y, Yang J, Yu YY. Pregnant Women during the novel coronavirus pneumonia epidemic: care management. Zhong Guo Liao Yang Yi Xue. 2020;29:361-3 Chinese.

48. Yang $X Q$, Zhang $Y Q$, Zhang WW, Shi Q, Zhao XX, Chao DL, et al. Responses and process recommendations of obstetrics in designated hospitals during the new coronavirus infection. Xian Dai Fu Chan Ke Jin Zhan. 2020;29:243-5 Chinese.

49. Chen J, Xiong M, He Z, Shi W, Yue Y, He M. The enclosed ward management strategies in psychiatric hospitals during COVID-19 outbreak. Glob Health. 2020;16(1):53. https://doi.org/10.1186/s12992-020-00586-z.

50. Zhang C, Sun Q, Feng L. Internet "cloud birth check" strategy during the prevention of new coronavirus infection in pregnant women. Xian Dai Fu Chan Ke Jin Zhan. 2020;29:165-6 Chinese.

51. Xu L, Ji B, Fang Y, Ge CL, Chen N. Evaluation of the "internet + pharmacy" intervention model on folic acid supplementation among pregnant women during the epidemic. Zhong Guo Yao Ye. 2020;29:43-5 Chinese.

52. Huang FL, Tai Y, Li RR, Duan YP, Shi YL, Ma LK. Case report during the prevention and control of the COVID-19 epidemic: multidisciplinary management of pregnancy comorbidities based on the internet platform. Zhong Guo Fu You Wei Sheng Za Zhi. 2020;11:83-8 Chinese.

53. Huang MJ, Qiu YC, Hu QB, Bian BY, Wang ZL, Wang ZJ, et al. Analysis of the prevention and control measures and medical resources of midwifery medical institutions during the epidemic period of new coronavirus infection in Guangdong province. Shi Yong Yi Xue Za Zhi. 2020;36:1277-81. https://doi.org/10.3969/j.issn.1006-5725.2020.10.003 Chinese.

54. Li XN, Ge JL. Emergency nursing management practice for prevention of new coronavirus hospital infection in general wards. Hu Li Xue Za Zhi. 2020; 35:69-71. https://doi.org/10.3870/j.issn.1001-4152.2020.07.069 Chinese.

55. Yang LY, Zhang F, Liu L, Zeng TY, Wang H. Emergency management for the prevention and control in delivery room during the outbreak of new coronavirus pneumonia. Hu Li Xue Za Zhi. 2020;35:66-8 Chinese.

56. Wu MY, Guo LD, Wang WZ, Chen CY, Wang GG, Zhu LF. Outpatient management and measures of a maternity hospital during the COVID-19 epidemic. Yi Yuan Guan Li Lun Tan. 2020;37:49-51 Chinese.

57. Wang Q, Kuang W, Ping W, Gao T, He ZP, Cai YX, et al. Clinical practice of prevention and treatment of cross-infection of new coronavirus pneumonia in the thoracic surgery ward. Zhong Guo Xiong Xin Xie Guan Wai Ke Lin Chuang Za Zhi. 2020;27:371-5. https://doi.org/10.7507/1007-4848.202002132 Chinese.

58. Yin Q, Sun Z, Liu T, Ni X, Deng $X$, Jia $Y$, et al. Posttraumatic stress symptoms of healthcare workers during the corona virus disease 2019. Clin Psychol Psychother. 2020;27(3):384-95. https://doi.org/10.1002/cpp.2477.

59. Zhu J, Sun L, Zhang L, Wang H, Fan A, Yang B, et al. Prevalence and influencing factors of anxiety and depression symptoms in the first-line medical staff fighting against COVID-19 in Gansu. Front Psychiatry. 2020;11: 386. https://doi.org/10.3389/fpsyt.2020.00386.

60. Neitzke AB. An illness of power: gender and the social causes of depression. Cult Med Psychiatry. 2016;40(1):59-73. https://doi.org/10.1007/s11013-015-94 66-3.

61. Huang L, Wang Y, Liu J, Ye P, Cheng B, Xu H, et al. Factors associated with resilience among medical staff in radiology departments during the outbreak of 2019 novel coronavirus disease (COVID-19): a cross-sectional study. Med Sci Monit. 2020;26:e925669. https://doi.org/10.12659/MSM.925669.

62. Xiao X, Zhu X, Fu S, Hu Y, Li X, Xiao J. Psychological impact of healthcare workers in China during COVID-19 pneumonia epidemic: a multi-center cross-sectional survey investigation. J Affect Disord. 2020;274:405-10. https://doi.org/10.1016/j.jad.2020.05.081.

63. Li G, Miao J, Wang H, Xu S, Sun W, Fan Y, et al. Psychological impact on women health workers involved in COVID-19 outbreak in Wuhan: a crosssectional study. J Neurol Neurosurg Psychiatry. 2020;91:895-7 BMJ Publishing Group Ltd.

64. Cai H, Tu B, Ma J, Chen L, Fu L, Jiang Y, et al. Psychological impact and coping strategies of frontline medical staff in Hunan between January and March 2020 during the outbreak of coronavirus disease 2019 (COVID-19) in Hubei, China. Med Sci Monit. 2020;26:e924171. https://doi.org/10.12659/ MSM.924171.

65. Addo PC, Jiaming F, Kulbo NB, Liangqiang L. COVID-19: fear appeal favoring purchase behavior towards personal protective equipment COVID-19. Serv Ind J. 2020;40(7-8):471-90. https://doi.org/10.1080/02642069.2020.1751823.

66. Bao H. "Anti-domestic violence little vaccine": a Wuhan-based feminist activist campaign during COVID-19. Interface. 2020;12:53-63. 
67. Zhu Z, Xu S, Wang H, Liu Z, Wu J, Li G, et al. COVID-19 in Wuhan: sociodemographic characteristics and hospital support measures associated with the immediate psychological impact on healthcare workers. EClinicalMedicine. 2020;24:100443.

68. Ju Y, Zhang Y, Wang X, Li W, Ng RMK, Li L. China's mental health support in response to COVID-19: progression, challenges and reflection. Glob Health. 2020;16(1):102. https://doi.org/10.1186/s12992-020-00634-8.

69. Liu M, Cheng S-Z, Xu K-W, Yang Y, Zhu Q-T, Zhang H, et al. Use of personal protective equipment against coronavirus disease 2019 by healthcare professionals in Wuhan, China: cross sectional study. BMJ. 2020;369 Available from: https://www.bmj.com/content/369/bmj.m2195.

70. Duan T, Jiang H, Deng $X$, Zhang Q, Wang F. Government intervention, risk perception, and the adoption of protective action recommendations: evidence from the COVID-19 prevention and control experience of China. Int J Environ Res Public Health. 2020;17(10):3387. https://doi.org/10.3390/ ijerph17103387.

71. Chao YP, Yan XW. Analysis of depression status and influencing factors of nurses in high-risk departments under the COVID-19 epidemic. Zhong Guo Yi Yao Dao Kan. 2020;22:294-300 Chinese.

72. Yu WL, Sun DY. Mental health risks and intervention strategies of front-line female nurses during new coronavirus pneumonia outbreak. Zhi Ye Wei Sheng Yu Ying Ji Jiu Yuan. 2020;38(151):106-8 Chinese.

73. Shi YQ, Dai XJ, Xu K, Xu K, Feng ZC. Psychological resilience among frontline female nurses during the new coronavirus pneumonia outbreak. Ji Nan Da Xue Bao (Zi Ran Ke Xue Yu Yi Xue Ban). 2020:41:366-76 Chinese.

74. Xiao C, Wang L, Liu JR, Shen XM, BR LI, Zhang SY, et al. Anxiety and depression of non-frontline medical staff during the new coronavirus pneumonia epidemic. Si Chuan Jing Shen Wei Sheng. 2020;33:15-8 Chinese.

75. Wei L, Shi LP, Chao J. Analysis of the psychological status of grassroots medical workers in Shanghai during the novel coronavirus pneumonia epidemic. Tong Ji Da Xue Bao (Yi Xue Ban). 2020;41:155-60. https://doi. org/10.16118/j.1008-0392.2020.02.003 Chinese.

76. Bo L. Investigation and analysis of the emergency response of male nurses during the outbreak of novel coronavirus pneumonia. Quan Ke Hu Li. 2020; 18:980-1 Chinese.

77. Zhang $Y H$, Tang L, Jiang C, Zhou CF, Lin WF, Wei YY, et al. Preliminary psychological distress of deployed nurses in remote areas: a survey. Hu Li Xue Za Zhi. 2020;35:5-8. https://doi.org/10.3870/j.issn.1001-4152.2020.05.005 Chinese.

78. Gao YL, Lin T, Chao Y, Li XM. The relationship between psychological distress, social support and psychological flexibility of male nurses in Sichuan Province during the epidemic. Cheng Du Yi Xue Yuan Xue Bao. 2020;15:178-181+188 Chinese.

79. Chen H, Sun L, Du Z, Zhao L, Wang L. A cross-sectional study of mental health status and self-psychological adjustment in nurses who supported Wuhan for fighting against the COVID-19. J Clin Nurs. 2020;29(21-22):416170. https://doi.org/10.1111/jocn.15444.

80. Jiang JM, Gan M, Zhu L, Wu WB, Lu JX. Professional identity and related factors of standardized training nurses during the novel coronavirus pneumonia epidemic. Cheng Du Yi Xue Yuan Xue Bao. 2020;15:289-92 Chinese.

81. Zhou PS, Yang CB, Li ZP, Li XR, Zhao WJ, Xin CY, et al. The participation of general medicine students in the COVID-19 epidemic and its impact on their professional identity. Wen Zhou Yi Ke Da Xue Bao. 2020;50:272-7, 284. https://doi.org/10.3969/j.issn.2095-9400.2020.04.004 Chinese

82. Liu C-Y, Yang Y, Zhang X-M, Xu X, Dou Q-L, Zhang W-W, et al. The prevalence and influencing factors in anxiety in medical workers fighting COVID-19 in China: a cross-sectional survey. Epidemiol Infect. 2020;148:e98. https://doi.org/10.1017/S0950268820001107.

83. Chen S, Li F, Lin C, Han Y, Nie X, Portnoy RN, et al. Challenges and recommendations for mental health providers during the COVID-19 pandemic: the experience of China's First university-based mental health team. Glob Health. 2020;16:59.
84. Lin K, McElmurry BJ, Christiansen C. Women and HIV/AIDS in China: gender and vulnerability. Healthc Women Int. 2007;28:680-99. https://doi.org/10.1 080/07399330701465010

85. Shapiro JR, Klein SL, Morgan R. Stop 'controlling' for sex and gender in global health research. BMJ Glob Health. 2021;6(4):e005714. https://doi.org/1 0.1136/bmjgh-2021-005714.

\section{Publisher's Note}

Springer Nature remains neutral with regard to jurisdictional claims in published maps and institutional affiliations.
Ready to submit your research? Choose BMC and benefit from:

- fast, convenient online submission

- thorough peer review by experienced researchers in your field

- rapid publication on acceptance

- support for research data, including large and complex data types

- gold Open Access which fosters wider collaboration and increased citations

- maximum visibility for your research: over $100 \mathrm{M}$ website views per year

At BMC, research is always in progress.

Learn more biomedcentral.com/submissions 